\title{
Porosities of building limestones: using the solid density to assess data quality
}

\author{
Christopher Hall $\cdot$ Andrea Hamilton
}

Received: 15 June 2015/ Accepted: 16 December 2015/Published online: 2 January 2016

(C) The Author(s) 2016. This article is published with open access at Springerlink.com

\begin{abstract}
A good knowledge of the volume-fraction porosity is essential in any technical work on porous materials. In construction materials the porosity is commonly measured by the Archimedes buoyancy method, from which the bulk density of the test specimen is also obtained. The porosity and the bulk density together fix the solid density of the specimen, as only two of the three quantities are independent. The solid density, although rarely discussed, is determined by the mineralogy of the specimen, and therefore can provide a valuable check on the accuracy of porosity and bulk density measurements. Our analysis of published data on calcitic limestones shows that the solid density is generally close to the ideal crystallographic density of calcite. Small deviations can often be traced to variations in mineral composition. However some published porosity-density data are inconsistent with the known mineralogy. Deviations which cannot be ascribed to composition may be assumed to arise from measurement errors. We show the value of using the solid density as a quality check on the measured porosity. We recommend that
\end{abstract}

C. Hall $(\bowtie)$

School of Engineering, University of Edinburgh, Edinburgh EH9 3FB, UK

e-mail: christopher.hall@ed.ac.uk

\section{A. Hamilton}

Department of Civil and Environmental Engineering, University of Strathclyde, Glasgow G1 1XJ, UK

e-mail: andrea.hamilton@strath.ac.uk the solid density should always be calculated for this purpose when the Archimedes method is used. This check can be useful also when porosities are measured by helium pycnometry or by mercury intrusion porosimetry.

Keywords Porosity · Density - Archimedes method · Limestone $\cdot$ Calcite

\section{Introduction}

Most inorganic construction materials, including the main building stones, are porous. In research on mechanics, transport, and durability in these materials, the porosity is often used as an explanatory (independent) variable, and so it is measured and reported as a material property. The porosity appears as a parameter in many technical calculations in building physics. There are now hundreds of publications containing porosity data, stretching back to the early method papers of Purdy and Moore [1], and of Washburn and his collaborators [2-4]. The data on construction materials form a subset of the larger resource that includes related work in geology, petrophysics, and industrial ceramics.

Unfortunately, reported porosity data are not always of high quality. Porosity values are sometimes inconsistent with the stated bulk densities and the known mineral compositions, and are therefore probably inaccurate. In this paper, we examine some published 
data on the porosities of limestones, a group of building materials where the material composition is often known, or can be assumed to lie within narrow limits. We aim to show that estimating the solid density from porosity and bulk-density data provides a simple quality check on the measured specimen porosity.

\section{Measuring the porosity}

\subsection{The Archimedes method}

The porosity of building stones is usually measured by the long-established Archimedes buoyancy methodsee $[5,6]$ for practical descriptions of such tests, and [7] for a recent discussion. Test procedures can be found in EN 1936 [8], which is the basis of many European national standards. Similar methods are described in EN 772 [9]. No equivalent American standard method exists for porosity in natural stone. In ASTM C97 [10] the bulk density is determined by a buoyancy method, but the porosity is not calculated.

In the Archimedes method three quantities are measured on a single specimen: $w_{\mathrm{d}}$, the weight of the dry specimen; $w_{\text {sat }}$, the weight in air of the specimen fully saturated with a liquid (usually water); and $w_{\mathrm{A}}$, the weight of the saturated specimen suspended and fully immersed in the saturating liquid. The last of these, $w_{\mathrm{A}}$, is known as the Archimedes weight. From these three quantities, the bulk density $\rho_{\mathrm{b}}$, the solid density $\rho_{\mathrm{s}}$, and the volume-fraction porosity $f$ of the specimen can be calculated from the following equations:

$$
\begin{aligned}
& \rho_{\mathrm{b}}=\frac{w_{\mathrm{d}} \rho_{\mathrm{w}}}{w_{\mathrm{sat}}-w_{\mathrm{A}}}, \\
& \rho_{\mathrm{s}}=\frac{w_{\mathrm{d}} \rho_{\mathrm{w}}}{w_{\mathrm{d}}-w_{\mathrm{A}}}, \\
& f=\frac{w_{\mathrm{sat}}-w_{\mathrm{d}}}{w_{\mathrm{sat}}-w_{\mathrm{A}}}=1-\frac{\rho_{\mathrm{b}}}{\rho_{\mathrm{s}}} .
\end{aligned}
$$

Here $\rho_{\mathrm{w}}$ is the density of the saturating liquid at the temperature of the measurement. Strictly, the quantity $f$ is the open porosity, the pore-space accessible to the saturating liquid. Any closed pores are treated as part of the solid material, and the solid density $\rho_{\mathrm{s}}$ is accordingly the density of the impermeable matrix, including any closed pores.

Equations 2 and 3 follow from the Archimedes buoyancy relations
$V_{\mathrm{s}}=\left(w_{\mathrm{d}}-w_{\mathrm{A}}\right) / \rho_{\mathrm{w}}$,

and

$V_{\mathrm{b}}=\left(w_{\mathrm{sat}}-w_{\mathrm{A}}\right) / \rho_{\mathrm{w}}$,

where $V_{\mathrm{s}}, V_{\mathrm{b}}$ are the solid and bulk volumes of the specimen. Of the quantitities $\rho_{\mathrm{s}}, \rho_{\mathrm{b}}$ and $f$, any two are independent (knowing two, the third is fixed). In publications providing porosity data, the bulk density is sometimes also reported. Surprisingly, the solid density is rarely given. Even if given, it is rarely the subject of much comment.

The Archimedes method is conceptually simple, but in practice prone to error. In measuring $w_{\mathrm{A}}$ and $w_{\text {sat }}$, it requires care to achieve complete saturation of the specimen using vacuum apparatus. To obtain $w_{\mathrm{d}}$, the specimen must be completely dried without thermal alteration of the material composition or structure. In measuring $w_{\text {sat }}$ liquid may be lost from the specimen by evaporation, or sometimes by drainage from low-suction cavities and cracks.

Equations 1-3 show how these three sources of measurement error affect the estimates of $f, \rho_{\mathrm{b}}$, and $\rho_{\mathrm{s}}$. (1) When the test specimen is not completely dried $w_{\mathrm{d}}$ is too high. It then follows that $\rho_{\mathrm{b}}$ is overestimated, while both $f$ and $\rho_{\mathrm{s}}$ are underestimated, as shown schematically in Fig. 1. (2) As discussed in [7], failing to saturate the specimen completely leaves the value of $\rho_{\mathrm{b}}$ unchanged, but leads to underestimates of both $f$ and $\rho_{\mathrm{s}}$. (3) Any loss of water from the surface of the saturated specimen before it is weighed in air means that $w_{\text {sat }}$ is too low. This causes the bulk volume $V_{\mathrm{b}}$ to be underestimated, and as a result $\rho_{\mathrm{b}}$ is overestimated, and $f$ underestimated, while the value of $\rho_{\mathrm{s}}$ is correct. None of these three measurement errors causes the solid density to be overestimated.

A serious practical problem in implementing the Archimedes method is that reference materials of certified porosity are not available. This makes traceable calibration difficult. The published literature also shows a wide variation in the estimates of uncertainty used by different authors in reporting porosity and density.

\subsubsection{Effects of measurement errors on porosity and density estimates}

We have indicated qualitatively how the calculated values of the bulk density, solid density and porosity are affected by the various measurement errors. In the 


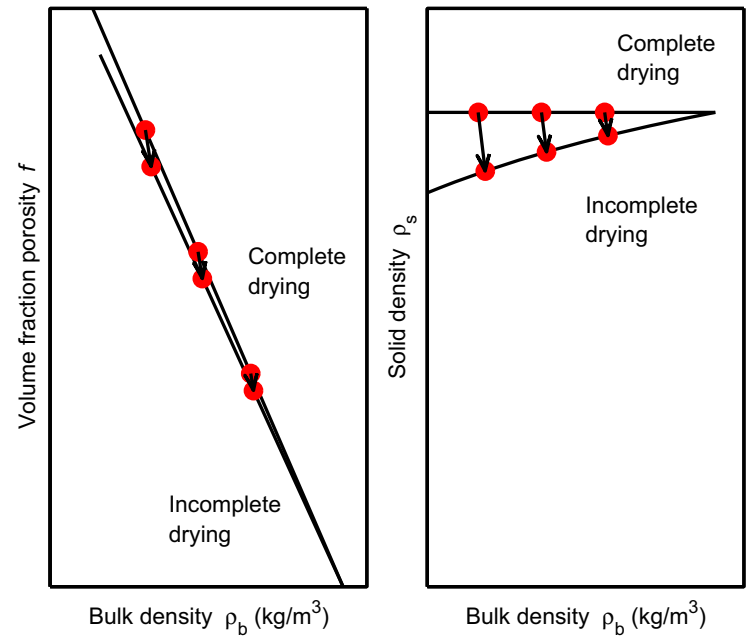

Fig. 1 A schematic to show the effect of incomplete drying on the estimates of bulk density, porosity, and solid density. Lines are calculated from Eqs. 1-3. If the drying is incomplete, the bulk density is overestimated while the porosity and the solid density are underestimated

Appendix we give the exact relations between the relative errors in the dry weight or in the saturated weight and the associated relative errors in the calculated quantities. The relative errors in the porosity and the solid density may sometimes be considerably larger than the relative errors in the measured weights. For example, in the case of incomplete saturation in a specimen with a solid density of $2500 \mathrm{~kg} / \mathrm{m}^{3}$ and porosity $0.2, \mathrm{a}-1 \%$ relative error in the saturated weight $w_{\text {sat }}$ leads to a $-11 \%$ relative error in the porosity. In a test in which the specimen is incompletely dried, $a+1 \%$ relative error in the dry weight leads also to a $-11 \%$ relative error in the porosity, and to a $-2 \%$ relative error in the solid density. Careful experimental technique is required to minimize such amplification in errors.

\subsection{The solid density, the real density and closed porosity}

In the Archimedes method, the solid density $\rho_{\mathrm{s}}$ is obtained from Eq. 2 (or in practice from Eq. 3). However the quantity $\rho_{\mathrm{s}}$ is not calculated in the test procedures of EN 1936, which instead describes a stand-alone method to determine the so-called real density $\rho_{\mathrm{r}}$ on a powdered specimen using a liquid pycnometer. Powdering is considered to remove closed porosity (although the evidence for this is not clear). The total porosity $f_{\mathrm{T}}$ is then calculated from Eq. 3: $f_{\mathrm{T}}=1-\rho_{\mathrm{b}} / \rho_{\mathrm{r}}$. It is unusual however for laboratories using the procedures of EN 1936 to report both open and total porosity. When both are determined, the difference $f_{\mathrm{T}}-f$ is used as a measure of $f_{\mathrm{c}}$, the volume-fraction closed porosity, although as the small difference of two experimental quantities it may be of low accuracy. Detecting and measuring closed porosity in stones and other porous inorganic materials is a difficult matter, for which there are no satisfactory general methods.

\subsection{Variants and alternatives}

In a variant of the Archimedes method, used when the specimen is in the form of a regular cylinder or a rectangular block, the bulk volume $V_{\mathrm{b}}$ is calculated directly from the specimen dimensions. The bulk density is then calculated from the formula $\rho_{\mathrm{b}}=$ $w_{\mathrm{d}} / V_{\mathrm{b}}$, and the porosity from the formula $f=1-$ $\left(w_{\mathrm{d}}-w_{\mathrm{A}}\right) /\left(\rho_{\mathrm{w}} V_{\mathrm{b}}\right)$. The saturated weight $w_{\text {sat }}$ is not required, although the specimen must be fully saturated in order to measure the Archimedes weight $w_{\mathrm{A}}$. This variant eliminates errors arising from problems in weighing the saturated specimen in air. These may be severe in specimens with coarse porosity which lose liquid by drainage.

An alternative to the standard Archimedes method is to obtain the open porosity $f$ by helium pycnometry [11], a technique often used in petrophysics but rarely for building materials. The solid volume $V_{\mathrm{s}}$ of the specimen is measured directly by expanding a known volume of helium gas into the open pores. Knowing the dry weight $w_{\mathrm{d}}$, we calculate the solid density $\rho_{\mathrm{s}}=w_{\mathrm{d}} / V_{\mathrm{s}}$. The porosity $f$ is then calculated from the formula $f=1-\rho_{\mathrm{b}} / \rho_{\mathrm{s}}$ (Eq. 3). All measurements are made on the dry specimen, and liquid saturation is not needed (although it may be used to obtain the specimen bulk volume $V_{\mathrm{b}}$ ). Assuming that the open pore-space is equally accessible to helium and to the saturating liquid used in the Archimedes method, the two methods measure the same porosity $f$ [11]. However, it is an open question whether this assumption is precisely true. Open porosities obtained by mercury-intrusion porosimetry may also be reported, but are often in poor agreement with Archimedes porosities where both are measured. 


\section{Limestones}

Limestones are an important group of building materials used throughout the world as dimension stones in masonry construction. In this paper, we use the term limestone to include also chalks, marbles, and travertines. In most building limestones, the main carbonate mineral is calcite, although there is a small subgroup in which it is dolomite. Many building limestones have high calcite contents, often over $90 \mathrm{wt} \%$, sometimes over $98 \mathrm{wt} \%$. Other minerals which may be found in the composition (usually in small quantities) are quartz, occasionally feldspars, and the high-density iron minerals haematite, goethite and siderite. Minor amounts of clays, notably illite, and micas such as glauconite, may also be present. When present, these minerals influence the density of the limestone, and their individual densities are listed in Table 1. The calcite phase in limestones is close to $\mathrm{CaCO}_{3}$ in composition, but may contain small amounts of substitutional $\mathrm{Mg}$. The effect of this is to increase slightly the mineral density, so that calcite containing $1.5 \mathrm{~mol} \% \mathrm{Mg}$ has a density of $2715 \mathrm{~kg} / \mathrm{m}^{3}$, compared with $2709 \mathrm{~kg} / \mathrm{m}^{3}$ for pure calcite.

If the mineral composition of a stone is known, we can calculate its composite mineral density [CMD], which we denote $\rho_{\mathrm{CM}}$. A specimen of solid volume $V_{\mathrm{s}}$ consists of $i$ mineral components, each of volume $V_{\mathrm{s} i}$, so that

$\rho_{\mathrm{CM}}=\sum v_{i} \rho_{i}$,

where $v_{i}=V_{\mathrm{s} i} / V_{\mathrm{s}}$ is the solid volume fraction of the component $i$, and $\rho_{i}$ its mineral density. (The CMD is the quantity that the real density $\rho_{\mathrm{r}}$ as defined

Table 1 Mineral densities [7, 12]

\begin{tabular}{ll}
\hline Mineral & Solid density $\left(\mathrm{kg} / \mathrm{m}^{3}\right)$ \\
\hline Calcite & 2709 \\
Dolomite & 2866 \\
Quartz & 2648 \\
Orthoclase & $\approx 2590$ \\
Siderite & 3944 \\
Haematite & 5275 \\
Goethite & 4269 \\
Illite & $\approx 2750$ \\
Kaolinite & $\approx 2645$ \\
Glauconite & $\approx 2675$ \\
\hline
\end{tabular}

operationally in EN 1936 aims to measure). The CMD of a pure calcite limestone is of course $2709 \mathrm{~kg} /$ $\mathrm{m}^{3}$. In the general case where the solid material incorporates closed pores, the volume-fraction closed porosity $f_{\mathrm{c}}=f_{\mathrm{T}}-f=\rho_{\mathrm{b}}\left(1 / \rho_{\mathrm{s}}-1 / \rho_{\mathrm{CM}}\right)$. Therefore the solid density $\rho_{\mathrm{s}}=\rho_{\mathrm{b}} \rho_{\mathrm{CM}} /\left(f_{\mathrm{c}} \rho_{\mathrm{CM}}+\rho_{\mathrm{b}}\right)$.

\subsection{Calcitic limestones}

We showed previously [7] that for 61 British and Irish calcitic limestones from the BRE Stone List [13] the relation between porosity and bulk density is well represented by the equation

$\rho_{\mathrm{b}}=C(1-f)$,

with $C=\rho_{\mathrm{c}}$, the solid density of calcite, $2709 \mathrm{~kg} / \mathrm{m}^{3}$. This equation follows of course from the second part of Eq. 3, setting $\rho_{\mathrm{s}}=\rho_{\mathrm{c}}$ for the particular case of calcitic limestones. What is surprising about the result reported in [7] is how little variation there is in the measured solid density in a large set of commercial limestones.

To these 61 limestones, we have now added data from other sources to make a larger porosity-density dataset of 117 calcitic limestones. All the additional data come from published research studies in which the materials and test methods are clearly described [7, 14-20]. All the sources use the Archimedes method of EN 1936, except [17] in which helium pycnometry is used. In Fig. 2 Left we see that the porosity-density data for the entire set lie close to the ideal calcite line. The best fit to Eq. 7 has $C=2708 \mathrm{~kg} / \mathrm{m}^{3}$, indistinguishable from the calcite line. The spread of the data is shown in Fig. 2 Right, where the solid density of each specimen, $\rho_{\mathrm{s}}=$ $\rho_{\mathrm{b}} /(1-f)\left(\right.$ Eq. 3 ) is plotted against $\rho_{\mathrm{b}}$. The median of $\rho_{\mathrm{s}}$ is $2709 \mathrm{~kg} / \mathrm{m}^{3}$, the same as the mineral density of calcite. The interquartile range (IQR), a measure of the spread in $\rho_{\mathrm{s}}$, is $12 \mathrm{~kg} / \mathrm{m}^{3}$, about $0.4 \%$ of the median. It is conventional to define outliers as datapoints which lie more than $1.5 \times \mathrm{IQR}$ above the first quartile, or 1.5 $\times$ IQR below the third quartile. By this definition, there are eight outliers in the set of 117 limestones, although these outliers are hard to discern in Fig. 2 Left. They are identified individually in the caption to Fig. 2. For the outlier Portland specimens 1, 3, there are no mineralogical reasons to expect an abnormal solid density. Outlier 2 is Ham Hill Lower Bed limestone. This is known to contain at least $90 \mathrm{wt} \%$ 
calcite, along with a small amount of goethite and quartz (DP Jefferson, private communication). The observed solid density is accounted for by $2.5 \mathrm{wt} \%$ goethite, and $5 \mathrm{wt} \%$ quartz. The Green Purbeck marble is described as containing iron-rich glauconite, although we have no compositional information on specimens tested. The two low outliers, 7, 8, are Monte Acuto specimens. The porosity data are reported to only two significant figures, so the uncertainty in the calculated solid density $\rho_{\mathrm{s}}$ is greater than for limestones from other sources.

It is interesting to compare the data of Fig. 2 with a dataset in which the solid density is obtained directly on crushed material, so perhaps reducing the possibility of including any closed porosity in $\rho_{\mathrm{s}}$. Bednarik et al. [21] report porosity data on 12 limestones from the Leitha formation in Austria using this method. To
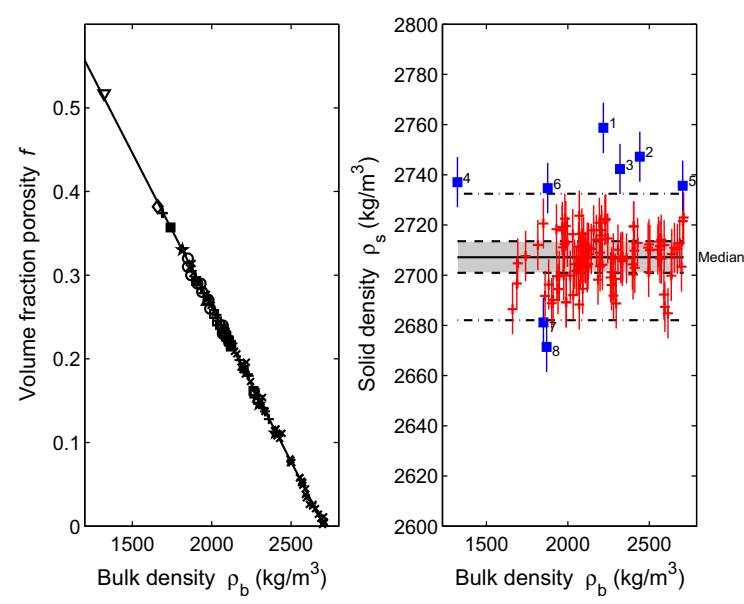

Fig. 2 Left Porosity $f$ vs bulk density $\rho_{\mathrm{b}}$ for 117 calcitic limestones. The stones included are: times symbol 61 British and Irish limestones from the BRE Stone List [13]; plus symbol 16 specimens of eight French and English limestones (Ancaster, Chauvigny, Clipsham, Massangis, Monk's Park, Portland, and Richemont) [7]; white circle 20 specimens of Portland limestone [15]; white up-pointing triangle 11 specimens of Monte Acuto limestone [17]; diamond Savonnières limestone [18]; white down-pointing triangle Savonnières limestone [14]; white square Maastricht limestone [16]; filled circle four French limestones (Euville, Savonnières, Massangis, Coulmier-le-Sec) [19]; filled square two Spanish limestones (Fraga Campanil, Santa Pudia) [20]. The solid line is the ideal calcite relation, Eq. 1, with $C=2709 \mathrm{~kg} / \mathrm{m}^{3}$. Right Solid density $\rho_{\mathrm{s}}$ versus bulk density $\rho_{\mathrm{b}}$ for the same 117 limestones. The median value of the solid density $\rho_{\mathrm{s}}$ is $2709 \mathrm{~kg} / \mathrm{m}^{3}$. The grey band shows the interquartile range, $12 \mathrm{~kg} / \mathrm{m}^{3}$. The solid squares mark outliers: 1 Portland Independent Whitbed, 2 Ham Hill Lower Bed, 3 Portland Bowers Base Bed, 4 Maastricht, 5 Green Purbeck Marble, 6 Totternhoe, 7, 8 Monte Acuto these, we can add also three high-calcite Spanish limestones for which real density data are given by Vázquez et al. [20]. For the Spanish stones, the calcite content is known by analysis to be $\geq 97 \mathrm{wt} \%$. As shown in Fig. 3, the data plot close to the ideal calcite line, with a small interquartile range. The only outlier is the Zeilerberg limestone of the Leitha group, with a solid density of $2671 \mathrm{~kg} / \mathrm{m}^{3}, 1.5 \%$ below the ideal calcite value. We have no quantitative mineralogical information on the Zeilerberg stone, but its petrographic description mentions the presence of quartz. The important conclusion is that these data (which are based on real density) closely resemble the large dataset of Fig. 2 (which is based on the Archimedes solid density). Both the solid density and the real density are the same as the calcite mineral density, so there is no indication of any closed porosity in these calcitic limestones.

Not all published porosity-density data on limestones conform closely to the pattern of Fig. 1. Figure 4 shows data on 23 British and Irish calcitic limestones from a reference source [22]. Here the spread about the ideal calcite line is large, with an interquartile range of $218 \mathrm{~kg} / \mathrm{m}^{3}$. There are a number of extreme outliers, and for many of the stones the
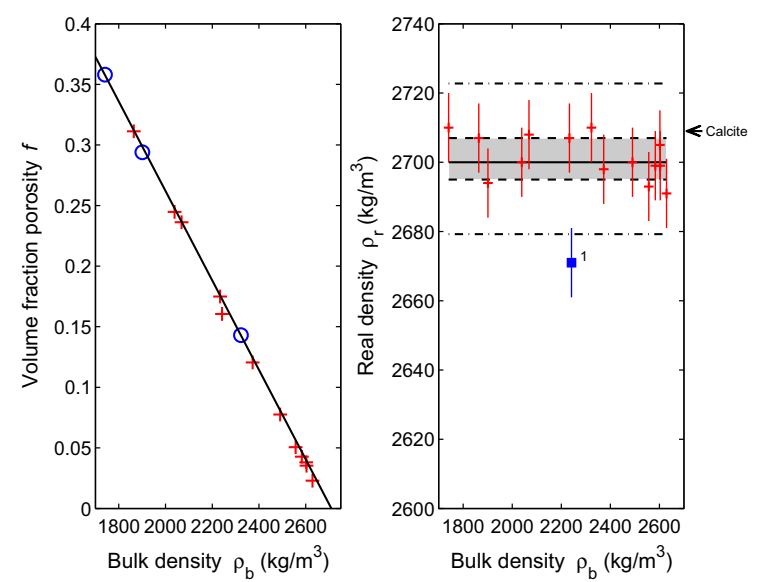

Fig. 3 Left Porosity $f$ versus bulk density $\rho_{\mathrm{b}}$ for 12 Leitha limestones [21] plus symbol and three Spanish limestones [20]. The points plotted for Leitha stones are the means of measurements on several specimens from each source (89 in total), and for the Spanish stones the means of nine specimens of each type. The solid line is the ideal calcite line, and not a regression line. Right Real density $\rho_{\mathrm{r}}$ versus bulk density $\rho_{\mathrm{b}}$ for the same 15 limestones. The median value of the solid density $\rho_{\mathrm{r}}$ is $2700 \mathrm{~kg} / \mathrm{m}^{3}$. The grey band shows the interquartile range, $12 \mathrm{~kg} / \mathrm{m}^{3}$. The outlier $l$ is from the Leitha Zeilerberg quarry (mean of 7 specimens) 
values of solid density calculated from the porosity and density cannot be reconciled with the known mineral composition.

We note that Mosch and Siegesmund [23] (see also Mosch [24]) have carried out statistical analyses of the technical properties of large number of building stones, including more than 200 limestones. Their graphs of porosity $v s$ bulk density show considerable scatter, but regression equations are not given. Neither the numerical values nor the sources of the data are stated. Therefore we cannot compare these analyses with the findings we report here.

\subsection{Portland limestone}

Portland stone is a high-calcite limestone which has been used in the construction of public buildings in Britain for many centuries [25]. Portland building stone is extracted at a number of quarries and mines on the Isle of Portland, Dorset, on the south coast of England. Stone is taken from three horizons at increasing depths, and designated as roach, whitbed and base bed respectively.

Because of its prominence and accessibility, Portland stone is often used in technical studies of stone behaviour and properties. Porosity-density data are available from many sources, both in the research literature and in technical data sheets from commercial suppliers. Although there are numerous petrographic descriptions of materials from different quarries and different geological horizons (see for example

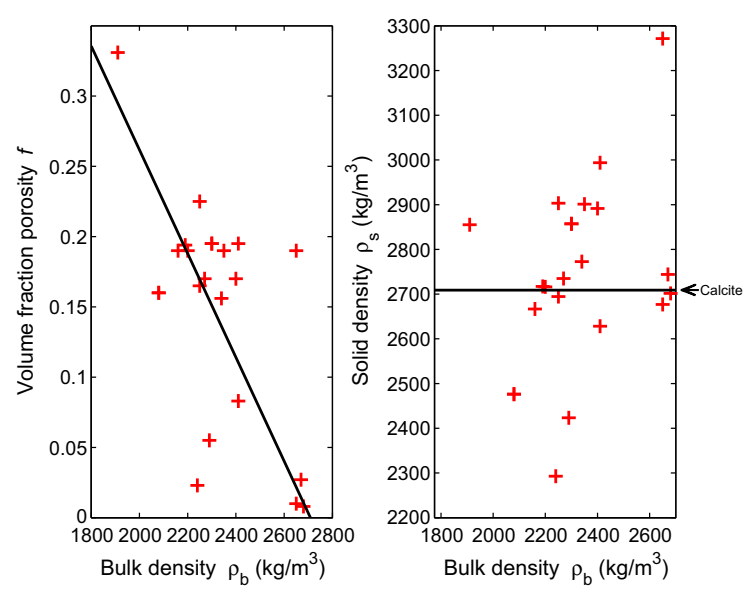

Fig. 4 Left Porosity $f$ versus bulk density $\rho_{\mathrm{b}}$ for 23 British limestones [22]. The solid line is the ideal calcite line. Right Solid density $\rho_{\mathrm{s}}$ versus bulk density $\rho_{\mathrm{s}}$ for the same stones
Cole [26] and Palmer [27]), quantitative mineralogical analysis is sparse. However there is broad agreement that the calcite content of Portland stone is generally at least $95 \mathrm{wt} \%$. Dubelaar et al. [15] report from XRF analysis that the Portland whitbed stone from Bowers Quarry has a calcite content of 97-98 wt\%, with 1-2 wt\% silica, and is "almost free of clay and iron minerals". Cole [26] found at least $98 \mathrm{wt} \%$ calcite in cores analysed by X-ray diffraction.

We have looked in detail at porosity-density data from the sources that we list in Table 2. In most cases, the solid density $\rho_{\mathrm{s}}$ is not reported, but we have calculated it from the published bulk-density and porosity data. The range of solid density is 2592-2759 $\mathrm{kg} / \mathrm{m}^{3}$, clustered around a median value of $2703 \mathrm{~kg} /$ $\mathrm{m}^{3}$, with five outliers, as shown in the box plot, Fig. 5 left. The low outliers 1, 3 come from the data of Cole [26], who made an extensive study of portlandian limestones in which porosity-density measurements were made on over 800 specimens. However, most were geological field specimens, and we include here only the three sets of data obtained on quarry stones. Fig. 5 Right shows the data of Cole and of Allison from Table 2. These $f-\rho_{\mathrm{b}}$ data lie slightly but distinctly below the ideal calcite line. The corresponding solid densities (see Table 2) are not consistent with the high calcite mineral composition. It could be argued that this is an indication of a small amount of closed porosity, but there is little evidence of that from other data on Portland stones.

We now exclude the outlier data, and consider the data from the central cluster only. Figure 6 shows that $f-\rho_{\mathrm{b}}$ data lie close to the ideal calcite line; there is a single marginal outlier, but this is a stone of unusually low porosity. The median solid density is $2705 \mathrm{~kg} / \mathrm{m}^{3}$, with an interquartile range of $7 \mathrm{~kg} / \mathrm{m}^{3}$. The median solid density is therefore only about $0.15 \%$ below the crystal density of mineral calcite. This difference sets an upper limit to the closed porosity $f_{\mathrm{c}}$, which therefore appears to be negligible in Portland stone.

\subsection{Maastricht limestone}

Maastricht limestone has been widely used as a dimension stone in Belgium [32], and has been the subject of several studies of water transport and durability. It is an exceptionally porous material, with $f$ as high as 0.55 . Maastricht stone is highly calcitic: Van Hees and Nijland [33] give $\mathrm{CaCO}_{3}$ contents of 
Table 2 Sources of porosity-density data for Portland stones

\begin{tabular}{|c|c|c|c|c|}
\hline Reference & Location/type & Solid density ${ }^{\mathrm{a}} \rho_{\mathrm{s}} \mathrm{kg} / \mathrm{m}^{3}$ & Methods & Comments \\
\hline \multirow[t]{3}{*}{ Cole [26] } & Perryfield WB & 2676 & A (paraffin) & $n=61$ \\
\hline & Perryfield BB & 2683 & & $n=27$ \\
\hline & Swanworth Purbeck & 2643 & & $n=28$ \\
\hline Allison [28] & Purbeck, U Jurassic & 2592 & A [29] & $n=10$ \\
\hline \multirow[t]{3}{*}{ Dubelaar et al. [15] } & Bowers Saunders WB & 2701 & A (EN 1936) & $n=4$ \\
\hline & Bowers Lynham WB & 2707 & & $n=12$ \\
\hline & Bowers BB & 2699 & & $n=4$ \\
\hline Ingham [30] & Coombefield WB & 2621 & A & \\
\hline \multirow[t]{10}{*}{ BRE Stone List [13] } & Admiralty $\mathrm{R}$ & 2704 & A (EN 1936) & \\
\hline & Bowers BB & 2742 & & \\
\hline & Bowers WB & 2711 & & \\
\hline & Fancy Beach BB & 2711 & & \\
\hline & Bowers Hard Blue & 2687 & & \\
\hline & Independent WB & 2759 & & \\
\hline & Perrycott & 2710 & & \\
\hline & Perryfield Shelly & 2707 & & \\
\hline & Coombefield WB & 2704 & & \\
\hline & Bowers Cap & 2692 & & \\
\hline \multirow[t]{5}{*}{ Stone Firms [31] } & Broadcroft WB & 2698 & A (EN 1936) & \\
\hline & Perryfield BB & 2703 & & \\
\hline & Perryfield R & 2700 & & \\
\hline & Perryfield Shelly & 2701 & & \\
\hline & Perryfield WB & 2703 & & \\
\hline Pugsley [7] & & 2709 & A & $n=2$ \\
\hline
\end{tabular}

$B B$ base bed, $R$ roach, $W B$ whitbed, $A$ Archimedes method, $n$ denotes the number of specimens, where reported

a Calculated from Eq. 3; where more than one specimen, the median value is given

95-98 wt\%, with the balance mainly as substitutional $\mathrm{Mg}$. The composite mineral density is therefore expected to be in the range $2710-2715 \mathrm{~kg} / \mathrm{m}^{3}$. Published density/porosity data are not entirely consistent. Cnudde et al. [16], using EN 1936 methods, report $f=0.517 \pm 0.008$, and $\rho_{\mathrm{b}}=1322 \pm 18 \mathrm{~kg} / \mathrm{m}^{3}$, values which correspond to a solid density $\rho_{\mathrm{s}}=2737 \pm 8 \mathrm{~kg} /$ $\mathrm{m}^{3}$, about $1 \%$ higher than the composite mineral density. On the other hand, Van Hees \& Nijland [33] give data based on RILEM CPC 11.3 methods which correspond to $\rho_{\mathrm{s}}=2653 \pm 6 \mathrm{~kg} / \mathrm{m}^{3}$, about $2 \%$ lower than the composite mineral density. A third study, by Rescic et al. [34], using helium pycnometry, reports solid densities for quarry and building specimens of 2680 and $2770 \mathrm{~kg} / \mathrm{m}^{3}$. Even allowing for some variability in the materials tested, it appears that the solid density of Maastricht stone is not known to better than about $\pm 3 \%$.

\subsection{Tuffeau limestones}

While Fig. 2 shows that a large number of the calcitic limestones used in construction have solid densities close to that of pure calcite, there are of course exceptions. Tuffeau is the name used to describe certain high-porosity siliceous limestones of northern France. The mineral composition is complex, and tuffeau stones typically contain only about $50 \mathrm{wt} \%$ calcite. For tuffeau quarry specimens from MarignyBrizay, Robert [35] found the Archimedes porosity $f=0.460$, and the solid density $\rho_{\mathrm{s}}=2550 \mathrm{~kg} / \mathrm{m}^{3}$ (mean values, $n=15$ ). The value of $\rho_{\mathrm{s}}$, although much lower than that of calcite, is consistent with the reported XRD mineral composition (wt $\%$ calcite 48; quartz 23; opal-CT 13; orthoclase 2; glauconite/ smectite clay 14). Allowing for some uncertainty in the individual densities of opal-CT $\left(\approx 2000 \mathrm{~kg} / \mathrm{m}^{3}\right)$, 

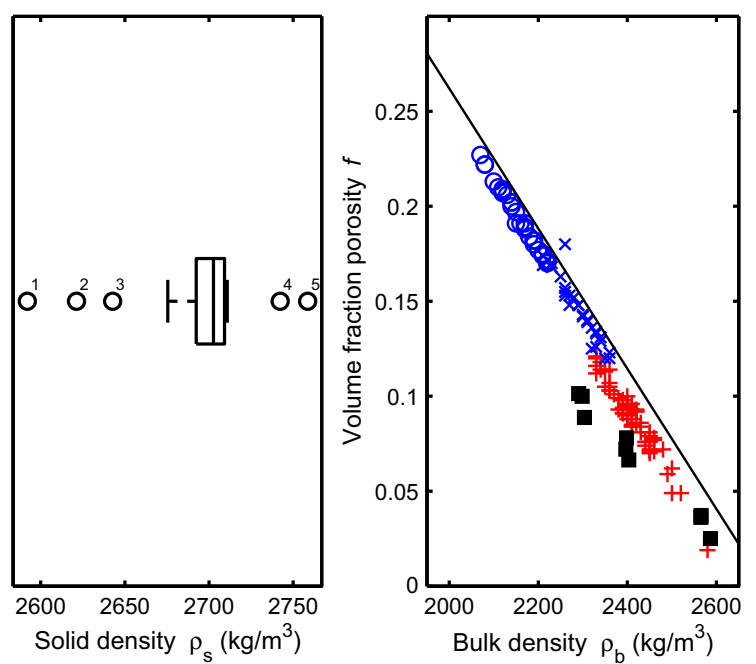

Fig. 5 Left Box plot of the solid density of Portland stones from sources listed in Table 2. The box shows the interquartile range, the central line marking the median. Outliers (white circle) are: 1 Purbeck, U Jurassic [28], 2 Coombefield WB [30], 3 Swanworth Purbeck [26], 4 Bowers Base Bed [13], 5 Independent WB [13]. Right Porosity $f$ versus bulk density $\rho_{\mathrm{b}}$ : data of Cole [26] for Swanworth (plus symbol), Perryfield WB (blue circle) and Perryfield BB (times symbol) Portland stones, and of Allison [28] (blue square) for Purbeck stone. The solid line is the ideal calcite line
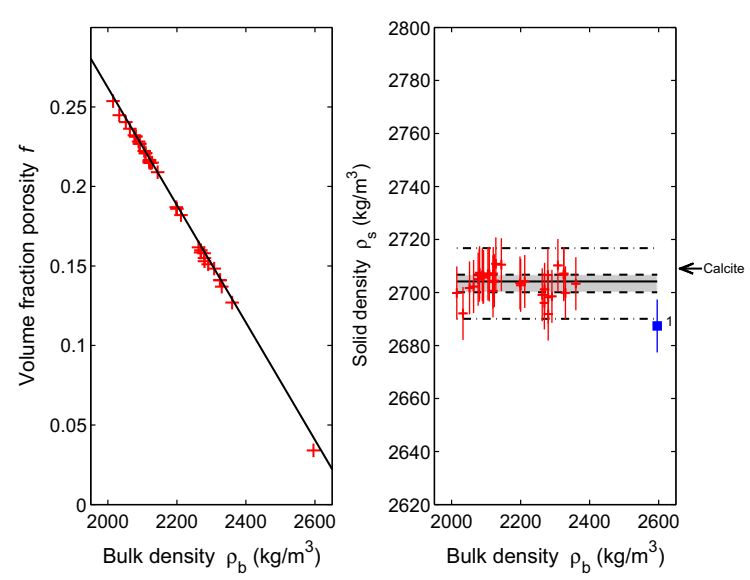

Fig. 6 Left Porosity $f$ versus bulk density $\rho_{\mathrm{b}}$ for Portland limestones, $n=38$, plus symbol. The solid line is the ideal calcite line. Right Solid density $\rho_{\mathrm{s}}$ versus bulk density $\rho_{\mathrm{b}}$ for the same stones. The median value is $2705 \mathrm{~kg} / \mathrm{m}^{3}$, the interquartile range $7 \mathrm{~kg} / \mathrm{m}^{3}$. The solid square marks one outlier: Bowers Hard Blue

and clay $\left(\approx 2300 \mathrm{~kg} / \mathrm{m}^{3}\right)$, we calculate a composite mineral density in the range $2570 \pm 30 \mathrm{~kg} / \mathrm{m}^{3}$, as found. Similar results have been obtained by
Beck et al. [36] on tuffeau specimens of similar composition from Saint-Cyr-en-Bourg.

\section{Recommendations for data checking}

From our analysis, we suggest that it is valuable to apply two procedures to check porosity-density data obtained by the Archimedes method.

First, in all cases, the solid density $\rho_{\mathrm{s}}$ should be calculated from the experimental data using Eq. 3 . This value should be checked for consistency with the composite mineral density. The CMD may be known from previous work on the same or similar materials, or may be calculated from mineralogical data on the specimen, for example by quantitative X-ray diffraction analysis. In the event that the $\rho_{\mathrm{s}}$ and $\rho_{\mathrm{CM}}$ differ significantly, then errors of type (1) and (2) in the Archimedes tests may be suspected. These concern incomplete drying and incomplete saturation of the specimen. If the difference persists, then the possibility of closed porosity should be considered.

Second, wherever possible the bulk volume of the specimen should be calculated by measuring the specimen dimensions, and this value of $V_{\mathrm{b}}$ compared with the Archimedes value obtained from Eq. 5. If the values differ significantly, errors in the measurement of the quantities $w_{\text {sat }}$ and/or $w_{\mathrm{A}}$ may have occurred. An error that arises in measuring $w_{\text {sat }}$, the saturated weight in air, does not produce an error in the solid density calculated from Eq. 2.

The solid density also provides a useful quality check when the porosity has been measured by a nonArchimedes method, such as mercury intrusion porosimetry or helium pyknometry. Provided that the bulk density has also been measured, then the solid density can be calculated from Eq. 3, and this should be compatible with the known mineral composition.

\section{Conclusions}

1. For calcitic limestones as a group, the published data show that the porosity and bulk density generally lie close to Eq. 7 with the constant $C$ close to the crystallographic density of calcite.

2. The solid density can provide a check on the accuracy of the porosity measurement because it should generally be possible to reconcile it with 
information about composition, mineralogy and microstructure.

3. A quantitative mineral composition, for example by quantitative Rietveld XRD, is an invaluable item of support information. This allows the solid density (the composite mineral density) to be estimated and compared with the solid density calculated from the bulk density and porosity.

4. If the Archimedes solid density is not consistent with the specimen mineralogy, then possible measurement errors should be considered.

5. Errors that arise from the drainage of saturating liquid from the specimen before weighing in air do not reveal themselves in an incorrect solid density. They can however be detected by comparing the Archimedes bulk volume with that measured directly from the specimen dimensions.

6. Any closed porosity is included in the solid matrix and contributes to the solid density. We do not see strong evidence for closed porosity in the calcitic limestones we analyze here, although of course it may be present in other stones, and in other construction materials such as fired-clay ceramics.

7. The solid density may also provide a useful test of data quality in measurements of porosity using other methods, such as helium pycnometry and mercury intrusion porosimetry.

These conclusions are supported here by our analysis of data on calcitic limestones, but the recommendations stand with equal force for all porous construction materials tested by the Archimedes method.

Acknowledgments We are grateful to the following for information and advice: Wim Dubelaar, Rob van Hees, Rudolf Holzer, David Jefferson, Roman Koch, Tim Palmer, Maurice Rogers, and Tiziana Vanorio.

Open Access This article is distributed under the terms of the Creative Commons Attribution 4.0 International License (http:// creativecommons.org/licenses/by/4.0/), which permits unrestricted use, distribution, and reproduction in any medium, provided you give appropriate credit to the original author(s) and the source, provide a link to the Creative Commons license, and indicate if changes were made.

\section{Appendix}

We discuss here how measurement errors affect the calculated bulk density, solid density, and porosity.
1. Incomplete drying Here there is an error in the measured dry weight $w_{\mathrm{d}}$. If the relative error $e_{w_{\mathrm{d}}}=\left(w_{\mathrm{d}}^{\prime}-w_{\mathrm{d}}\right) / w_{\mathrm{d}}$, where $w_{\mathrm{d}}^{\prime}$ denotes the erroneous dry weight and $w_{\mathrm{d}}$ the true value, then it follows directly from Eq. 1 that the relative error in the bulk density is the same, that is $e_{\rho_{\mathrm{b}}}=e_{w_{\mathrm{d}}}$. However, the relative errors in the porosity and solid density are more complicated in form. Thus, $e_{f}=-e_{w_{\mathrm{d}}}\left(\rho_{\mathrm{s}} / \rho_{\mathrm{w}}\right)(1-f) / f$. A positive relative error in the dry weight leads to a numerically larger negative relative error in the porosity. The relative error in the calculated solid density $e_{\rho_{\mathrm{s}}}=$ $\left[(1-f) e_{\rho_{\mathrm{b}}}+f e_{f}\right] /\left[1-f\left(e_{f}+1\right)\right]=\left[-\left(\rho_{\mathrm{s}}-\rho_{\mathrm{w}}\right)\right.$ $\left.e_{w_{\mathrm{d}}}\right] /\left[\rho_{\mathrm{w}}+\rho_{\mathrm{s}} e_{w_{\mathrm{d}}}\right]$. Since $\rho_{\mathrm{s}}>\rho_{\mathrm{w}}$, a positive relative error in the dry weight leads to a negative (and somewhat larger) relative error in the solid density.

2. Incomplete saturation Here there is an error in the measured saturated weight $w_{\text {sat }}$; however the quantity $w_{\text {sat }}-w_{\mathrm{A}}$ is unaffected by this error. It follows from Eq. 1 that the relative error in the bulk density $e_{\rho_{\mathrm{b}}}$ is zero. However a relative error in the saturated weight $e_{w_{\text {sat }}}=\left(w_{\text {sat }}^{\prime}-w_{\text {sat }}\right) / w_{\text {sat }}$ produces errors in the calculated porosity and the calculated solid density. Thus, $e_{f}=(1-$ $f)\left(\rho_{\mathrm{s}} / \rho_{\mathrm{w}}\right) e_{w_{\text {sat }}} / f$. Since $e_{w_{\text {sat }}}$ is necessarily negative, $e_{f}$ is likewise negative, but numerically larger. The relative error in the solid density $e_{\rho_{\mathrm{s}}}=\rho_{\mathrm{s}} e_{w_{\mathrm{sat}}} /\left(\rho_{\mathrm{w}}-\rho_{\mathrm{s}} e_{w_{\mathrm{sat}}}\right)$. Since $\rho_{\mathrm{w}}$ is generally much greater than $\rho_{\mathrm{s}} e_{w_{\text {sat }}}$, a negative relative error in the saturated weight leads to a negative, and numerically larger, relative error in the solid density.

3. Loss of water in a nominally saturated specimen Here there is an error in the measured saturated weight $w_{\text {sat }}$; however there is no associated change in the Archimedes weight $w_{\mathrm{A}}$. In this case, it is obvious from Eq. 2 that the relative error in the solid density, $e_{\rho_{\mathrm{s}}}$, is zero. However a relative error in the saturated weight $e_{w_{\text {sat }}}$ produces a relative error in the bulk density $e_{\rho_{\mathrm{b}}}=-e_{w_{\text {sat }}} /\left[e_{w_{\text {sat }}}+\rho_{\mathrm{w}} /\right.$ $\left.\left[(1-f) \rho_{\mathrm{s}}+f \rho_{\mathrm{w}}\right]\right]$. Thus a negative relative error in the weight of the specimen weighed in air produces a positive relative error in the bulk density. The magnitudes of the two relative errors are usually similar. The associated relative error in the porosity $e_{f}=-(1-f) e_{\rho_{\mathrm{b}}} / f$. Since $e_{\rho_{\mathrm{b}}}$ is 
positive, $e_{f}$ is negative and numerically larger than $e_{\rho_{\mathrm{b}}}$.

\section{References}

1. Purdy RC, Moore JK (1907) Pyro-chemical and physical properties of clays. Trans Am Ceram Soc 9:204-318

2. Washburn EW (1921) Porosity: I. Purpose of the investigation. II. Porosity and the mechanism of absorption. J Am Ceram Soc 4:916-922

3. Washburn EW, Footitt FF (1921) Porosity: III. Water as an absorption liquid. J Am Ceram Soc 4:527-537

4. Washburn EW, Bunting EN (1922) Porosity: V. Recommended procedures for determining porosity by methods of absorption. J Am Ceram Soc 5:48-56

5. Ross KD, Butlin RN (1989) Durability tests for building stone, Building Research Establishment report 141. BRE, Watford

6. RILEM (1984) CPC 11.3 Absorption of water by immersion under vacuum. Mater Struct 17:391-394

7. Hall C, Hamilton A (2015) Porosity-density relations in stone and brick materials. Mater Struct 48:1265-1271

8. European Standard EN 1936: 2006 Natural stone test methods - determination of real density and apparent density, and of total and open porosity

9. European Standard EN 772-4: 1998 Methods of test for masonry units-part 4: determination of real and bulk density and of total and open porosity for natural stone masonry units

10. ASTM C97 (2009) Standard test methods for absorption and bulk specific gravity of dimension stone

11. Hall C, Hoff WD (2012) Water transport in brick, stone and concrete, 2nd edn. Taylor and Francis, London/New York

12. Robie RA, Bethke PM, Beardsley KM (1967) Selected $\mathrm{X}$-ray crystallographic data, molar volumes, and densities of minerals and related substances. Geological Survey Bulletin 1248, US Government Printing Office, Washington

13. http://projects.bre.co.uk/ConDiv/stonelist/stonelist.html

14. Roels S (2000) Modelling unsaturated moisture transport in heterogeneous limestone. $\mathrm{PhD}$ thesis, Catholic University of Leuven

15. Dubelaar CW, Engering S, Van Hees RPJ, Koch R, Lorenz H-G (2003) Lithofacies and petrophysical properties of Portland base bed and Portland whit bed limestone in relation to durability. HERON 48:221-229

16. Cnudde V, Dierick M, Vlassenbroeck J, Masschaele B, Lehmann E, Jacobs P, Van Hoorebeke L (2007) Determination of the impregnation depth of siloxanes and ethylsilicates in porous material by neutron radiography. J Cult Herit 8:331-338

17. Vanorio T, Mavko G (2011) Laboratory measurements of the acoustic and transport properties of carbonate rocks and their link with the amount of microcrystalline matrix. Geophysics 76:E105-E115

18. Derluyn H (2012) Salt transport and crystallization in porous limestone: neutron-X-ray imaging and poromechanical modeling. PhD thesis, ETH Zurich

19. De Kock T, Dewanckele J, Boone M, De Schutter G, Jacobs P, Cnudde V (2014) Replacement stones for Lede stone in
Belgian historical monuments. In: Cassar J, Winter MG, Marker BR, Entwistle NRG, Bromhead EN, Smith JWN (eds) Stone in historical buildings: characterization and performance. Geological Society, London, pp 31-46 (Special Publication)

20. Vázquez P, Alonso FJ, Carrizo L, Molina E, Cultrone G, Blanco M, Zamora I (2013) Evaluation of the petrophysical properties of sedimentary building stones in order to establish quality criteria. Constr Build Mater 41:868-878

21. Bednarik M, Moshammer B, Heinrich M, Holzer R, Laho M, Rabeder J, Uhlir C, Unterwurzacher M (2014) Engineering geological properties of Leitha Limestone from historical quarries in Burgenland and Styria, Austria. Eng Geol 176:66-78

22. Smith MR (ed) (1999) Stone: building stone, rock fill and armour stone in construction. Geological Society, London, Engineering Geology Special Publications no 16, Appendix $\mathrm{C}$

23. Mosch S, Siegesmund S (2007) Statistisches Verhalten petrophysikalischer und technischer Eigenschaften von Naturwerkstein. Zeitschrift der Deutschen Gesellschaft für Geowissenschaften 158:821-868

24. Mosch S (2008) Optimierung der Exploration, Materialcharakterisierung von Naturwerkstein. $\mathrm{PhD}$ thesis, Göttingen

25. Hughes T, Lott GK, Poultney MJ, Cooper BJ (2013) Portland stone: a nomination for "Global Heritage Stone Resource" from the United Kingdom. Episodes 36:221-226

26. Cole DI (1971) Ultrasonic velocity measurements on limestones from the Portland group: correlation with porosity and other lithological factors. $\mathrm{PhD}$ thesis, University of Southampton

27. Palmer TJ (2005) Limestone petrography and durability in English Jurassic freestones. In: Doyle P (ed) England's heritage in stone. English Stone Forum, Folkestone, pp 6678

28. Allison RJ (1987) Non-destructive determination of Young's modulus and its relationship with compressive strength, porosity and density. In: Jones ME, Preston RMF (eds) Deformation of sediments and sedimentary rocks. Geological Society, London, pp 63-69 (Special Publication)

29. Carter ME, Matthews AP (1977) The measurement of porosity of irregular vugular rock samples using a modified liquid saturation technique. Géotechnique 27:435-438

30. Ingham JP (2005) Predicting the frost resistance of building stone. Q J Eng Geol Hydrogeol 38:387-399

31. Stone Firms Ltd, technical datasheets

32. Dubelaar CW, Dusar M, Dreesen R, Felder WM, Nijland TG (2006) Maastricht limestone: a regionally significant building stone in Belgium and The Netherlands. In: Fort R, Alvarez de Buergo M, Gomez-Heras M, Vazquez-Calvo C (eds) Heritage, weathering and conservation. Taylor \& Francis, London, pp 9-14

33. Van Hees RPJ, Nijland TG (2009) Assessment of the state of conservation of a Middle Neolithic flint mine in Maastricht limestone. HERON 54:227-250

34. Rescic S, Fratini F, Tiano P (2010) On-site evaluation of the 'mechanical' properties of Maastricht limestone and their relationship with the physical properties. In: Smith BJ, Gomez-Heras M, Viles HA, Cassar J (eds) Limestone in the built environment: present-day challenges for the 
preservation of the past. Geological Society, London, pp 203-208 (Special Publication)

35. Robert R. (2004) Analytical characterization of porous geomaterials: reference assessment in some sedimentary rocks. $\mathrm{PhD}$ thesis, Humboldt University, Berlin
36. Beck K, Al-Mukhtar M, Rozenbaum O, Rautureau M (2003) Characterization, water transfer properties and deterioration in tuffeau: building material in the Loire valley-France. Build Environ 38:1151-1162 